\title{
Reducing maternal and child mortality in Balochistan: The untapped potential of family planning
}

\author{
Zeba Sathar \\ Population Council \\ Maqsood Sadiq \\ Seemin Ashfaq \\ Population Council
}

Follow this and additional works at: https://knowledgecommons.popcouncil.org/departments_sbsr-rh

Part of the Demography, Population, and Ecology Commons, Family, Life Course, and Society Commons, International Public Health Commons, Maternal and Child Health Commons, and the Women's Health Commons How does access to this work benefit you? Let us know!

\section{Recommended Citation}

Sathar, Zeba, Maqsood Sadiq, and Seemin Ashfaq. 2015. "Reducing maternal and child mortality in Balochistan: The untapped potential of family planning," Policy brief. Islamabad: Population Council, The Evidence Project. 


\section{RETHINKING THE ROLE OF FAMILY PLANNING IN BALOCHISTAN'S HEALTH STRATEGY}

Among the four provinces of Pakistan, Balochistan confronts the highest incidence of preventable deaths among mothers, infants, and young children. Maternal deaths account for 35 percent of mortality among women of reproductive age (PDHS 2007). In 2012, the maternal mortality ratio (MMR) was estimated at 996 per 100,000 births (Sathar, Wazir and Sadiq 2014); the infant mortality ratio (IMR) was 97 per 1,000 births; and the under-five mortality ratio (U5MR) was 111 per 1,000 births (PDHS 2013). The ratios currently translate into an annual death toll of nearly 3,000 women, 28,600 infants and 4,000 children (aged 1-4), primarily due to conditions that could easily be prevented with basic healthcare.

Unfortunately, this situation appears poised to worsen as maternal and child health indicators in the province are deteriorating. Skilled birth attendance rose from 8 percent in 1990-91 to 23 percent in 2006-07, but then fell to 18 percent by 2012-13 (PDHS). Similarly, the proportion of women receiving antenatal care went up from 10 percent in 199091 to 41 percent in 2006-07, only to drop to 31 percent by 2012-13 (PDHS). Complete immunization among children aged 12 to 23 months has increased from 24 percent in 2001 but only up to 41 percent at present (PIHS/PSLM 2001-02 and 2013-14). The contraceptive prevalence rate (CPR) in the province is also the lowest in the country: in the past 15 years, it has increased by less than a percentage point a year from 12 percent in 2000-01 to a mere 20 percent in 2012-13 (Fig. 1).

Not surprisingly, while Balochistan's estimated MMR dropped steeply between 2001 and 2006, it has since rebounded (Fig. 2). Similarly, the province's infant and child (under 5 years of age) mortality ratios were declining until 2006-07 but started to climb after 2006 (Fig. 3).

The good news is that the Balochistan Health Sector Strategy for 2013-2018 reflects a high resolve to reverse these trends. Its central goal is "to reduce morbidity and mortality rates, especially the neonatal and infant mortality rates and the maternal mortality ratio, and to contribute in improving the quality of services and meeting the targets set under the Millennium Development Goals." By 2018, the strategy aims

\section{BOX 1}

\section{IGNORED AT PERIL}

Evidence for family planning's

massive potential to reduce

maternal and child mortality

It is estimated that between 1990 and 2010 , contraceptive use has accounted for about 40 percent of the reduction in maternal deaths in developing countries; if all the unmet need for contraception in the world were fulfilled, a further 30 percent reduction in maternal deaths would be achieved (Cleland et al. 2012). Moreover, voluntary family planning could eliminate the 13 percent of maternal deaths that occur due to unsafe abortions and 36 percent of maternal deaths caused by unintended pregnancies (Bongaarts et al. 2012).

In the specific case of Pakistan, Ahmed et al. (2012) estimate that family planning averted 42 percent of maternal deaths in 2008 (with a CPR of 29.2 percent).

Birth spacing has also been recognized as one of the strongest interventions to improve child survival rates. According to Rutstein (2008), birth intervals of 33 months would reduce the U5MR by 13 percent, and, in Pakistan, neonatal, infant, and child mortality are almost halved when birth intervals are 4 years or more, compared to when they are less than 2 years.

to lower the IMR to 65 per 1,000 live births; while it does not specify an MMR target, the government is pursuing the Millennium Development Goal (MDG) of 140 per 100,000 live births. The strategy recognizes the ineffectiveness of the current institutional structure for delivery of maternal, neonatal and child health $(\mathrm{MNCH})$ health services and proposes a holistic, systems approach for rectifying this and other longstanding issues leading to low access, quality and provision of health services in Balochistan. 


\section{FIGURE 1: CONTRACEPTIVE PREVALENCE IN BALOCHISTAN (\%)}

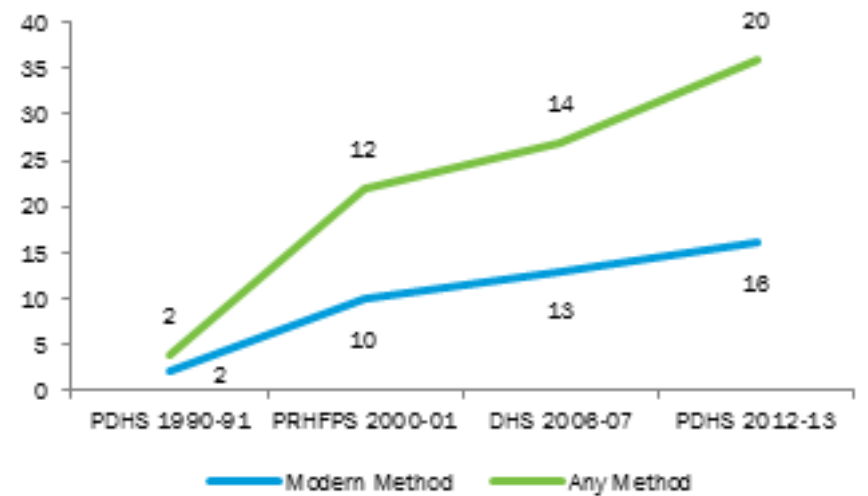

To meet its ambitious MMR, IMR and U5MR targets, the government must leverage every promising intervention at its disposal. Family planning offers an extremely effective but as yet underutilized route for achieving huge reductions in maternal and child mortality.

As health planners in Balochistan identify the priority interventions for improving maternal and child health in the province, it is essential that they be informed of the enormous potential of family planning in this context. Contraceptive use tends to be viewed as a measure for managing population growth in Pakistan but there is strong evidence to warrant its repositioning in health strategy as a critical $\mathrm{MCH}$ tool (Box 1). It is internationally recognized that women face significantly heightened risks of pregnancy-related death when they are too young (less than 18 years) or too old (more than 34 years) at the time of birth; when the birth interval is less than 33 months; and when parity exceeds three children (Box 1). In addition, every unintended pregnancy represents an unnecessary risk, which escalates when a woman resorts to induced abortion-especially when the procedure is performed in unsafe settings, as is typically the case in Pakistan.

Furthermore, we now know that children's risk of dying in infancy or before the age of five is strongly correlated with the same high-risk fertility behaviors that endanger mothers' lives. The strong association between maternal health and
FIGURE 2: MATERNAL MORTALITY RATE IN BALOCHISTAN - TRENDS \& TARGETS

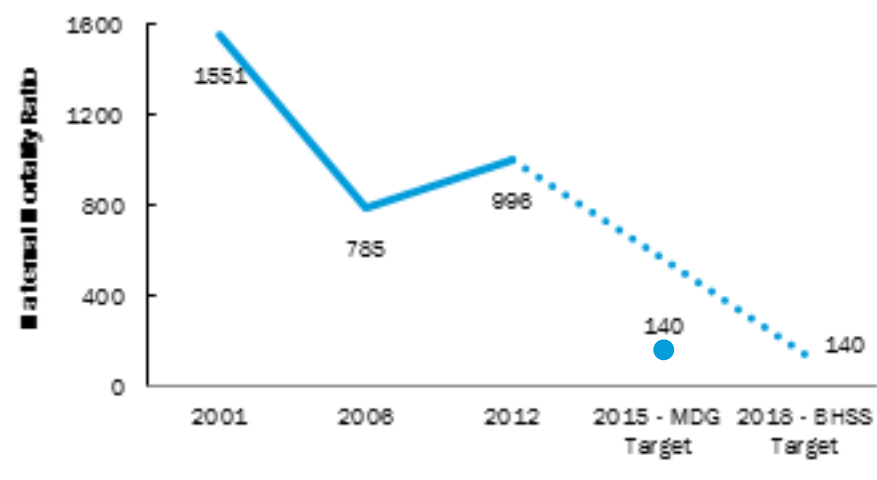

Maternal mortality ratio (Dotted as estim ated/prọected)

Note: Dotted as estimated/projected

Sources: PDHS 2013 and Health Sector Strategy - Balochistan Province (BHSS) 2013

FIGURE 3: INFANT AND UNDER-FIVE MORTALITY RATIO IN BALOCHISTAN - TRENDS \& TARGETS

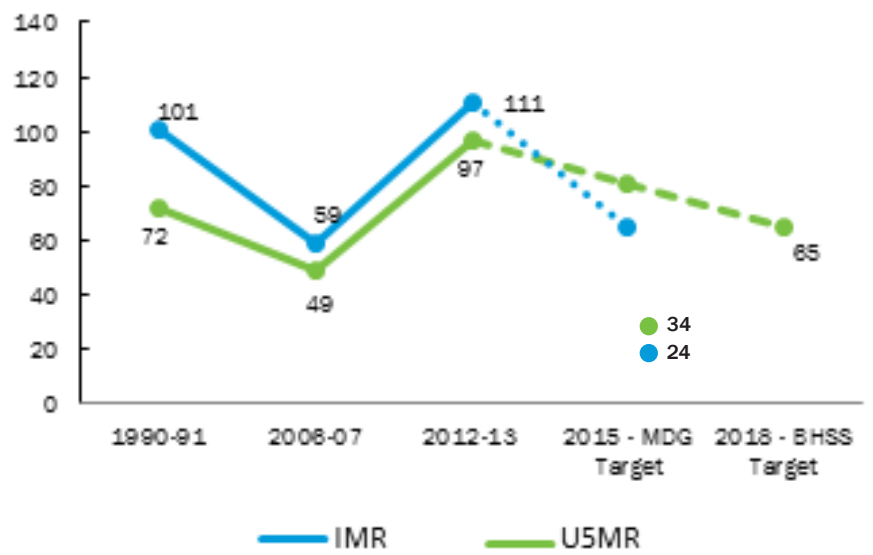

Note: Dotted as estimated/projected

Sources: PDHS 2013 and Health Sector Strategy - Balochistan Province (BHSS) 2013

infant survival, particularly for neonates, is the basis of the Healthy Spacing and Timing of Pregnancies (HSTP) initiative launched by the World Health Organization (WHO).

In order to meet its ambitious goals of reduced infant and maternal mortality, the Government of Balochistan will need to leverage every promising intervention at its disposal. Family planning offers an extremely effective but as yet untapped route for getting there. 


\section{FIGURE 4: FERTILITY PREFERENCES OF WOMEN IN BALOCHISTAN (\%) 2012-2013}

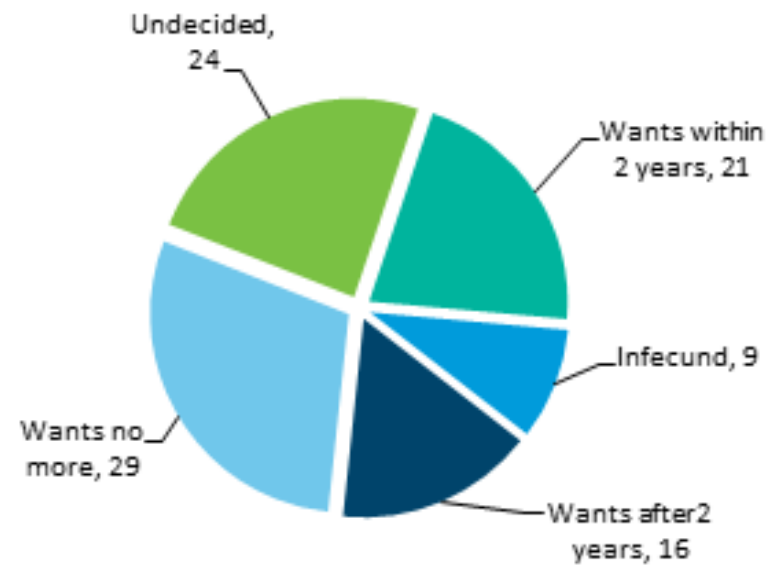

Source: PDHS 2013

\section{FIGURE 5: THE GAP BETWEEN FAMILY PLANNING DEMAND AND USE IN BALOCHISTAN (\%)}

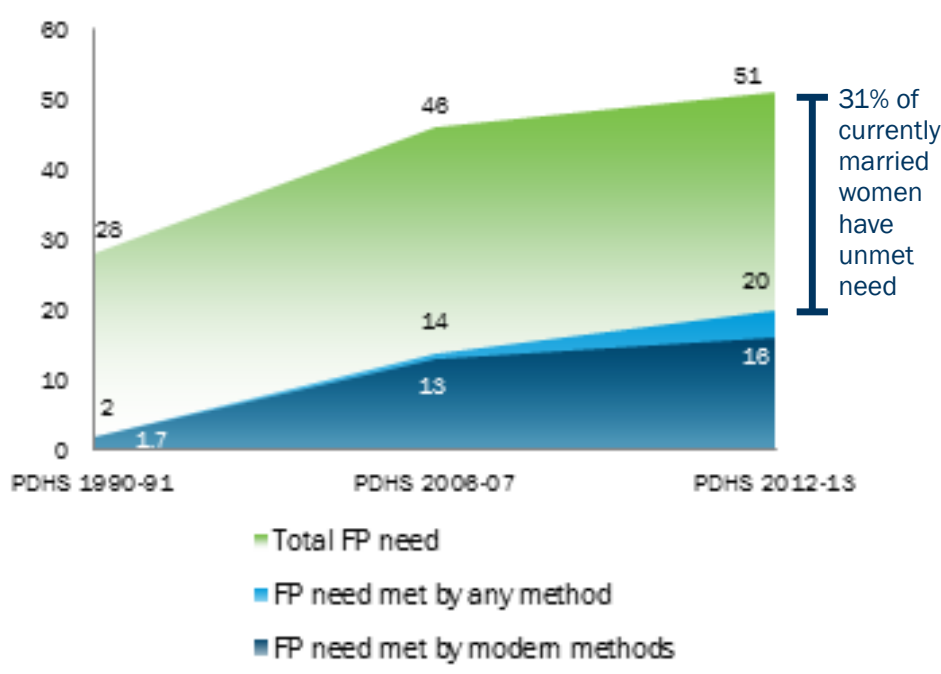

Source: PDHS 2013

\section{IMPROVING MATERNAL AND CHILD SURVIVAL IN BALOCHISTAN THROUGH FAMILY PLANNING}

A significant proportion of men and women in Balochistan would like to avoid the high-risk fertility behaviors that threaten maternal and child health. It is estimated that 45 percent of women wish to limit or delay births by two years (Fig. 4), and this desire is shared by 39 percent of men (PDHS 2013). In addition, nearly a quarter of married women are undecided about whether and when to have a child.

Worryingly, however, these healthier fertility preferences are not translating into practice. Surveys show that 51 percent of married women of reproductive age (MWRA) in Balochistan would like to use contraceptives to space or limit births. However, only 20 percent are using any family planning method (Fig. 5). The proportion of women using reliable modern methods is even smaller, i.e., 16 percent. More than half of total family planning need in Balochistan is currently unmet, with 31 percent of MWRA not using any method, modern or traditional, even though they wish to space or limit births. A significant increase in contraceptive prevalence can be achieved capitalizing on this group even without extensive demand generation efforts.

The gap between family planning demand and need also means, however, that a large proportion of MWRA in Balochistan are unable to practice healthy spacing and timing of pregnancies, which exposes them and their young children to the following sources of mortality risks:

1. Unintended pregnancies - The province's total fertility rate (TFR) is 4.2 while the estimated average number of children wanted by women is 3.4 (PDHS 2012 13). About a third of the 0.5 million pregnancies that occur in the province every year are unintended and, on average, every woman of reproductive age faces the unnecessary risk and physical burden of one unintended pregnancy.

2. Unsafe induced abortions - Due to unwanted pregnancies, there were more than 136,000 induced abortions in Balochistan in 2012, resulting in over 47,000 cases of post-abortion complications (PAC). 
With 20 out of every 1,000 women of reproductive age seeking treatment, the province accounted for 7 percent of the PAC caseload for the entire country (Population Council 2014).

3. Adolescent pregnancy - At the time of the 2012-13 PDHS, 6.8 percent of women (aged 15-19) had begun childbearing. Among every 1,000 women in this age group, 44 had given birth in urban areas and 55 in rural areas. These young women face special health risks that are further aggravated by poverty and relatively lower access to $\mathrm{MCH}$ services.

4. Infants of teenaged mothers - Data from the other three provinces of Pakistan shows that neonatal mortality is much higher among children of teenaged mothers than among those born to women aged 2029 years (Sathar, Wazir and Maqsood 2014). Unfortunately, owing to limitations in data concerning infant mortality in Balochistan, the prevalence of this association in the province cannot be clearly established. Nevertheless, the global and national evidence suggest strongly that neonatal mortality may be higher among teenaged mothers in Balochistan.

FIGURE 6: NEONATAL AND POST-NEONATAL MORTALITY RATIOS IN BALOCHISTAN BY MOTHERS' AGE AT BIRTH (DEATHS PER 1,000 LIVE BIRTHS)

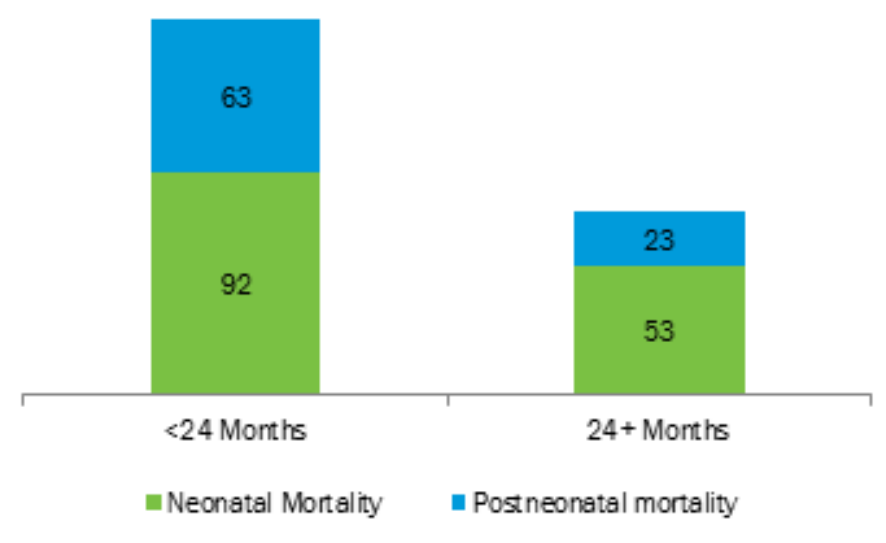

Source: PDHS 2013
5. Late childbearing - According to PDHS 2013, some 15 percent of women in Balochistan had given birth after the age of 35. Late childbearing is associated with heightened risks of maternal and infant health issues.

6. High parity - PDHS 2013 found that 53 percent of women in Balochistan had given birth to four or more children. This situation exposes mothers as well as infants and young children to heightened risks of malnutrition and health complications.

7. Short birth intervals - To give mothers the best chance to maintain sound health while delivering and raising healthy children, WHO recommends an interval of at least 33 months between births. Birth spacing is also known to play an important role in the nutritional status of children under 5 years of age, with shorter birth intervals increasing the risk of low weight, at birth and beyond, as well as stunting. However, slightly over 39 percent of women in Balochistan gave birth less than 24 months after a previous birth, while 75 percent gave birth less than 36 months after the previous birth (PDHS 2013)

The above-outlined risks, which lead to maternal, infant and young child mortality, can be addressed through family planning. To prevent the mortality associated with high-risk fertility behavior, the existing demand for family planning must be fulfilled at the earliest by eliminating current unmet need. In the longer run, the public must be educated about the necessity of healthy spacing and timing of pregnancies so that demand for contraception increases to cover the complete family planning needs of all MWRA. Increased use of family planning would not only prevent the mortality and sickness caused by high-risk fertility behavior, it would also reduce the pressure of unintended pregnancies and births, and associated maternal and child morbidity on the health system. 
MEASURING THE POWERFUL LIFE-SAVING POTENTIAL

\section{OF FAMILY PLANNING IN}

\section{BALOCHISTAN}

In 2014, the Population Council, Pakistan conducted a study to estimate the size of reductions achievable in maternal, infant, and child mortality in Balochistan through increased family planning (Sathar, Wazir and Sadiq 2014). Simulations were conducted to gauge the change in maternal, infant, and child mortality when existing unmet need for family planning (31 percent) is reduced or eliminated by raising the CPR.

In the case of maternal mortality, the study examined the effect of eliminating unmet need by raising the CPR from its existing level of 20 percent to 51 percent (Scenario 1 in Fig. 7 ). For comparison purposes, the effect of increasing skilled birth attendance from its present level of 18 percent to 60 percent was also examined (Scenario 2).

To measure the impact of family planning on infant and child mortality, simulations of two scenarios were conducted-one in which unmet need was reduced by raising the CPR to 36 percent (Scenario 1 in Figs. 7 and 8) and the second in which unmet need was completely eliminated by raising the CPR to 51 percent (Scenario 2).
The study arrived at the following eye-opening conclusions:

\section{Reduction Achievable in Maternal Mortality}

- Eliminating unmet need for family planning would prevent $\mathbf{4 1}$ percent of maternal deaths (Fig. 7)

- Raising skilled birth attendance from 18 to 60 percent would prevent 39 percent of maternal deaths (Fig. 7)

- Eliminating unmet need and simultaneously increasing skilled birth attendance to 60 percent would prevent 68 percent of maternal deaths (Fig. 7)

\section{Reduction Achievable in Infant Mortality}

- Reducing unmet need for family planning by increasing the CPR to 36 percent would reduce infant mortality by 22 percent (Fig. 8)

- Eliminating unmet need altogether would reduce infant mortality by $\mathbf{4 1}$ percent (Fig. 8)

These findings show that family planning programs should be an equally important component of improving maternal health and reducing maternal and child mortality. In fact, greater reductions in maternal mortality can be achieved by eliminating unmet need for family planning than by increasing skilled birth attendance.

FIGURE 7: MATERNAL LIVES THAT CAN BE SAVED ANNUALLY IN BALOCHISTAN BY INCREASING CONTRACEPTIVE PREVALENCE AND SKILLED BIRTH ATTENDANCE
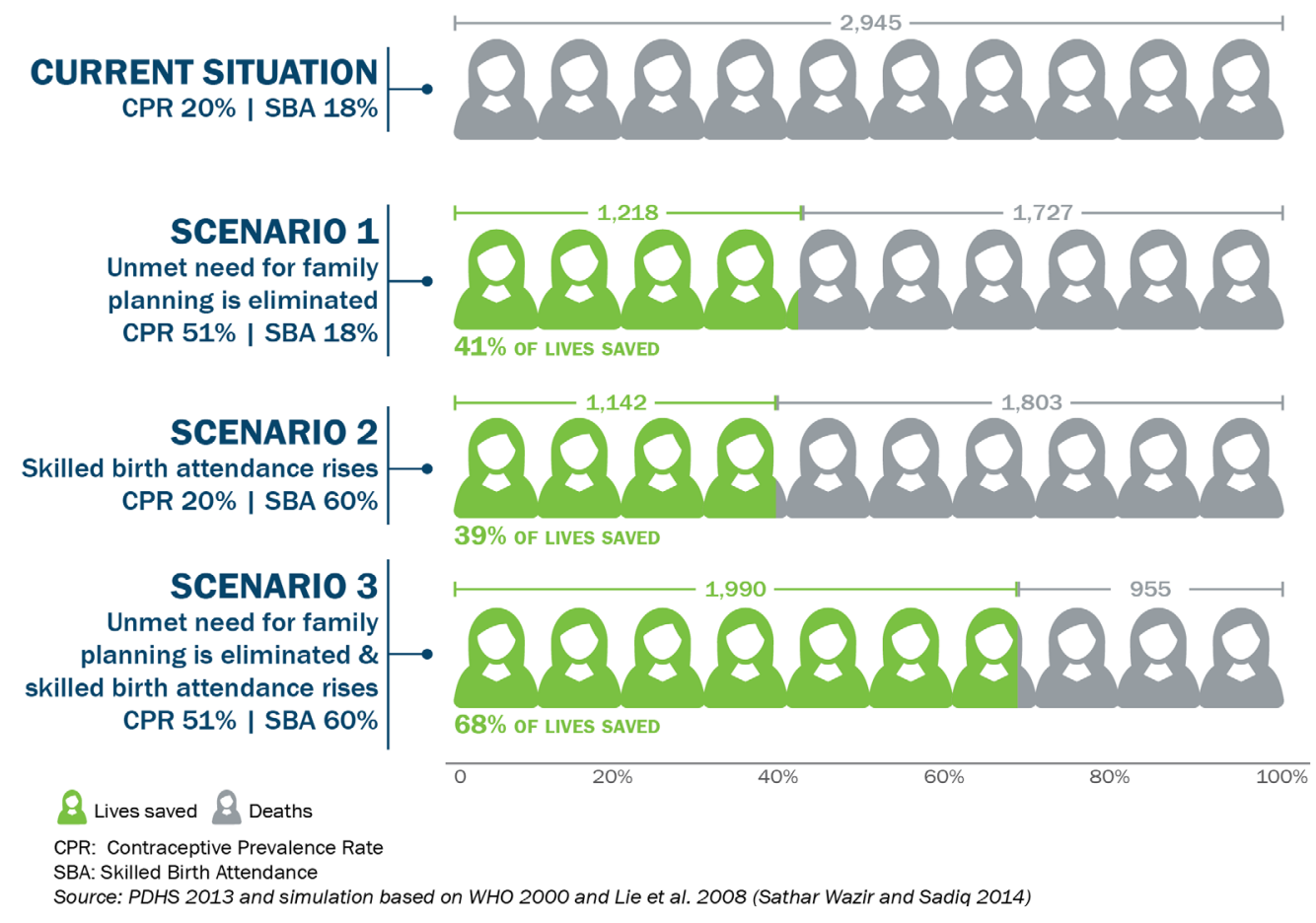
FIGURE 8: INFANT LIVES THAT CAN BE SAVED ANNUALLY IN BALOCHISTAN BY INCREASING CONTRACEPTIVE PREVALENCE

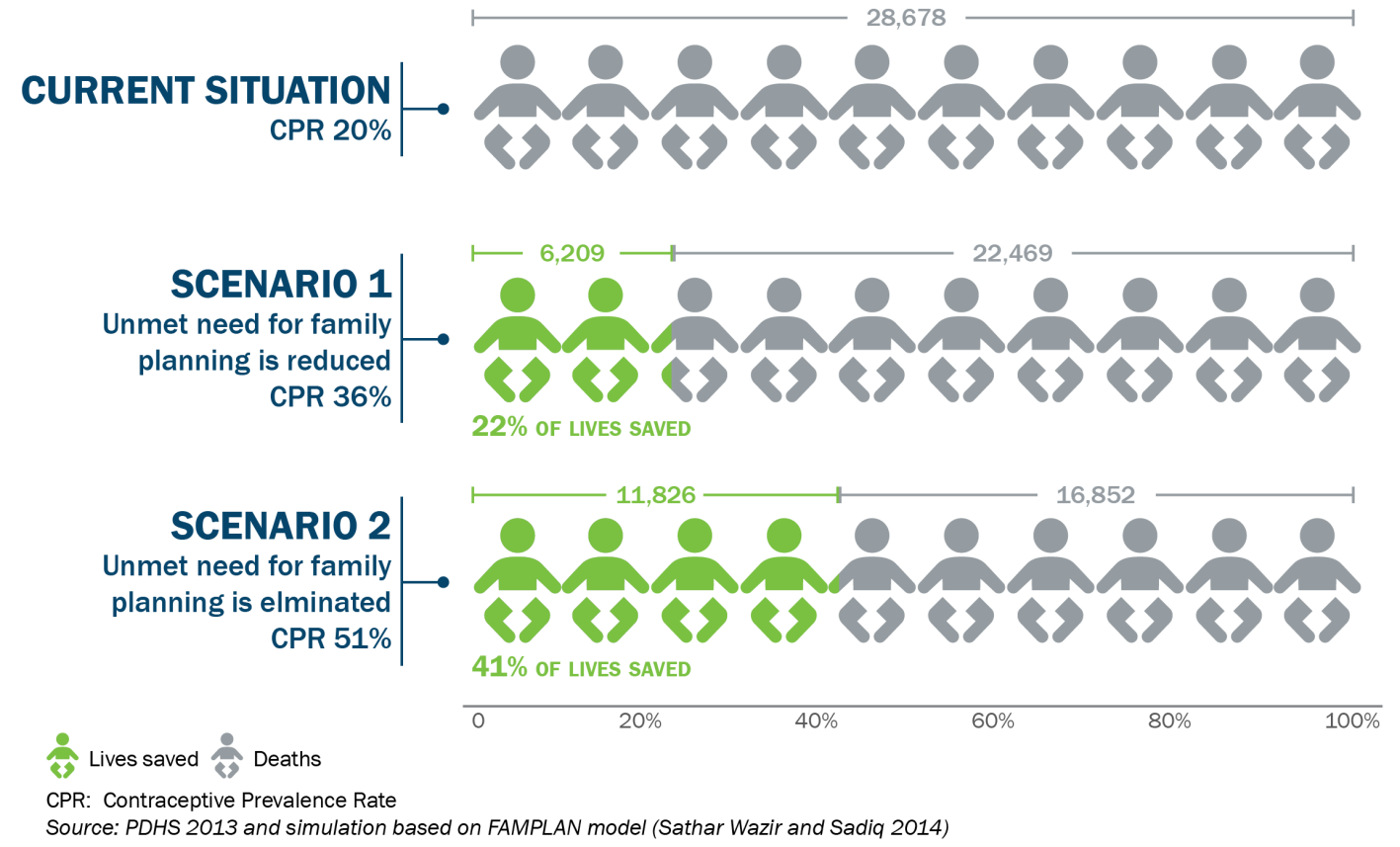

\section{POLICY IMPLICATIONS}

For a rapid reduction in maternal, infant, and child mortality to the levels targeted for 2018 and onwards, the most effective strategies for improving $\mathrm{MCH}$ need to be galvanized in Balochistan. The evidence shows that family planning is one of the most powerful tools at the government's disposal. Simply by fulfilling the existing unmet need for birth spacing and limiting-which would mean raising the CPR to 51 percent-it is possible to prevent 41 percent of maternal deaths, 35 percent of infant deaths, and 74 percent of young child deaths. This will lead to proportionate declines in the maternal, infant and child mortality ratios of the province. Notably, more women's lives can be saved in this manner than by increasing skilled birth attendance from 18 to 60 percent.

Family planning's wider health benefits further justify its immediate prioritization. These include, for example, reduced anemia among women; lower numbers of underweight, wasted and stunted children; and reduced burden on antenatal, obstetric, postnatal and post-abortion services.

Moreover, family planning is highly cost-effective: every dollar spent on this intervention saves nearly four dollars that would otherwise be spent on maternal health, immunization, malaria, water and sanitation, and education (Bongaarts 2012).

In view of its strong health benefits, family planning must be swiftly repositioned in provincial policy as a key mother and child health intervention. It should be a priority element of the government's envisaged Essential Package of Health Services (EPHS) for primary and secondary healthcare, especially in rural areas. The government's plans to revitalize and expand the role of lady health workers should likewise include a clear focus on provision of family planning services.

To ensure that family planning finds its due place in Balochistan's development framework, it is also vital to recognize its profound links with the government's wider socioeconomic aims and policies. The benefits of family planning in terms of increased women's empowerment, female participation in the workforce, household savings, poverty reduction, and school enrollment are well-documented (Sathar, Wazir and Sadiq 2014). These gains will be most visible when interventions are targeted at the segments of Balochistan with the greatest unmet need for family planning: the less developed districts; the rural areas; poor communities; and young, uneducated women 


\section{REFERENCES}

Ahmed, S., Li, Q., F., Liu, L., \& Tsui, A. 2012. Maternal deaths averted by contraceptive use: An analysis of 172 countries. The Lancet, 380, 111-125.

Cleland, J., Conde-Agudelo, A., Peterson, H., Ross, J., \& Tsui, A. 2012. Contraception and health. The Lancet, 380, 149-156.

Government of Balochistan. 2013. Health Sector Strategy - Balochistan Province.

National Institute of Population Studies (NIPS) [Pakistan] and ICF International. 2013. Pakistan Demographic and Health Survey 2012-13. Islamabad, Pakistan, and Calverton, Maryland, USA: NIPS and ICF International.

Pakistan Bureau of Statistics. 2002. Pakistan Integrated Household Survey (PIHS) 2001-02. Statistics Division, Government of Pakistan, Islamabad.

Pakistan Bureau of Statistics. 2014. Pakistan Social \& Living Standards Measurement Survey (PSLM) 2013-14. Statistics Division, Government of Pakistan, Islamabad.
Population Council. 2014. Induced Abortions and Unintended Pregnancies in Pakistan, 2012. Islamabad.

Rutstein, S. 0. 2008. Further evidence of the effects of preceding intervals on neonatal, infant and under-five-years mortality and nutritional status in developing countries: Evidence from demographic and health surveys (Demographic and Health Surveys Working Paper No, 41). Calverton, MD: Macro International Inc.

Sathar Z.A., Wazir, M.A., and Sadiq, M. 2014. Prioritizing family planning for achieving provincial maternal child health and development goals. Islamabad: Population Council.

WHO. 2000. Maternal Mortality 2000: Estimates developed by WHO, UNICEF and UNFPA. Retrieved from http://whqlibdoc.who.int/publications/2004/9241562706.pdf?ua=1 (accessed March 2014).

\section{THE EVIDENCE PROJECT}

Population Council House No. 7, Street No. 62

Section F-6/3 Islamabad, Pakistan tel +92518445566 evidenceproject.popcouncil.org

\section{CONTRIBUTORS}

Dr. Zeba A Sathar (T.I.)

Maqsood Sadiq Seemin Ashfaq
The Evidence Project is made possible by the generous support of the American people through the United States Agency for International Development (USAID) under the terms of cooperative agreement no. AID-OAA-A-13-00087. The contents of this document are the sole responsibility of the Evidence Project and Population Council and do not necessarily reflect the views of USAID or the United States Government.

Evidence

The Evidence Project uses implementation science-the strategic generation. translation, and use of evidence-to strengthen and scale up family planning and reproductive health programs to reduce unintended pregnancies worldwide. The Evidence Project is led by the Population Council in partnership with INDEPTH Network, International Planned Parenthood Federation, Management Sciences for Health, PATH, Population Reference Bureau, and a University Research Network.

(c) 2015 The Population Council, Inc.

Suggested Citation: Sathar, Zeba A., Maqsood Sadiq, and Seemin Ashfaq. "Reducing maternal and child mortality in Punjab: The untapped potential of family planning," Policy Brief. Islamabad, Pakistan: Population Council, Evidence Project. 